\title{
Ultimate Collapse Strength Assessment of Damaged Steel-Plated Structures
}

\author{
Underwood James $\mathrm{M}^{\mathrm{a}, *}$, Sobey Adam $\mathrm{J}^{\mathrm{a}}$, Blake James I R ${ }^{\mathrm{a}}$, Shenoi R. Ajit ${ }^{\mathrm{a}}$
}

${ }^{\text {a }}$ Fluid Structure Interactions Research Group, University of Southampton, United Kingdom

*Corresponding Address: Fluid Structure Interactions Research Group, University of Southampton, Building 28/1015, University Road, Southampton, SO17 1BJ, United Kingdom.

Tel: +442380597773

Fax: +44 2380597744

email: j.m.underwood@ soton.ac.uk

\begin{abstract}
In an unpredictable world where human intervention or unexpected environmental conditions can prevail, damage can occur to manmade structures. Whilst structural design allows for redundancy, or a structural capability beyond the general working load of the structure, it is necessary to be able to analyse and understand the residual capability of a damaged structure to ensure the safety of personnel in the vicinity of the structure and assess the potential to facilitate repair.
\end{abstract}

Idealised Structural Unit Method (ISUM) can allow rapid assessment of large structural arrangements by simplification into smaller constituent parts, which are assessed against pre-calculated failure data for each part. The method has potential benefits for allowing rapid assessment of damaged steelplated structure that would otherwise require the use of high fidelity modelling of the entire structures, such as through the use of finite element analysis.

This paper presents a study on the use of ISUM to assess damaged steel-plated structures and its limitations through the collapse analysis of stiffened steel panels. A new ISUM is proposed for strength assessment of damaged structural arrangements. Analysis is undertaken to assess the effects of geometrical and material property variations that can occur in a structure as well as the effects of damage aperture size and shape on the collapse strength of stiffened steel panels. The study shows 
that while ISUM can be applied in the assessment of damaged steel-plated structures, implementing the proposed new ISUM allows greater accuracy in the calculation of the collapse strength of damaged stiffened steel panels. The paper also concludes that the assessment of larger structural units for application in the ISUM assessment, will allow the effects of the damage on surrounding structure to be captured, which can influence the deflection shapes that will lead to collapse of the structure.

\section{Keywords}

Idealised Structural Unit Method (ISUM), Ultimate Collapse Strength, Damaged Steel-Plated Structures.

\section{Introduction}

In an unpredictable world where human intervention or unexpected environmental conditions can prevail, damage can occur to manmade structures. Whilst structural design will allow for redundancy or a structural capability beyond the general working load of the structure, it is necessary to be able to analyse and understand the residual capability of a damaged structure to ensure the safety of personnel in the vicinity of the structure, limit any potential environmental impact the damage may cause and assess the potential to facilitate repair. Some examples of this requirement for the assessment of damaged steel structures are presented by Mahin [1] on the damage to steel structures during the Northridge earthquake and Heneka et al. [2] on the assessment of storm damage to buildings. Furthermore, Fam et al. [3] state that forty percent of all steel bridges in the US are classified as structurally deficient or structurally obsolete and work to investigate damage events in shipping [4], indicate the need to be able to assess the residual strength of structures to allow upgrade and repair or to ensure safe operation.

The analysis of damaged steel structures is further complicated by potential variation between the as built and current condition of the structure, for example variations in material properties or in plate thicknesses due to rolling tolerances or age factors such as corrosion can significantly affect the residual strength of the structure. However, these attributes may not be able to be assessed due to the inability to survey the area. 
When rapid modelling of a damaged structure is required, high fidelity structural modelling, such as by Finite Element Analysis (FEA) (which is often used to interrogate damage events at a later stage $[5,6,7])$, is not possible due to the long lead time to provide dependable results; therefore, simplified modelling methods are required to estimate the damage condition and residual strength; a view echoed in the ISSC 2009 report into damage assessment after accidental events [8]. Idealised Structural Unit Method (ISUM), initially proposed by Ueda et al. in 1974 [9], is now a well established method of performing a simplified analysis of complex structural arrangements, particularly in the assessment of intact ship and offshore structures $[10,11,12]$, providing dependable results much faster than is achievable by FEA and can be seen to have similar applicability to the assessment of bridges, silos, water storage tanks, warehouses, etc. While this method has found success due to its rapid assessment and assumed conservative nature, it is believed that the assumptions that are currently made to apply the method to model and assess damaged structural arrangements, limit the ISUM's potential in this environment.

This paper presents a study of the application of ISUM to the assessment of damaged steel-plated structures, through the collapse analysis of damaged stiffened steel panels under combined lateral and axial loading. Modelling of the collapse analysis also accounts for a number of different variables including, damage size, shape and location, variation in plating thickness and variation in material properties. A new ISUM is proposed for the assessment of damaged steel structures to improve accuracy of the modelling of the damaged structure and its application is investigated.

\section{Structural Modelling}

\subsection{Idealised Structural Unit Method}

Originally proposed by Ueda et al. [9], ISUM is described as an efficient method of analysing the non-linear behaviour until collapse of structures [13]. In contrast to FEA, whereby the structural response is assessed by discretising the known structural arrangement into small elements with multiple degrees of freedom, ISUM reduces the number of degrees of freedom so that the number of unknowns in the finite stiffness matrix decreases. This is achieved by modelling the object structure 
with large structural units whose structural response behaviour is known under a given load application $[14,15]$.

Steel-plated structures are fundamentally constructed of large steel plates, stiffened through the welded attachment of appropriately sized and spaced stiffeners of rectangular bar, L-shaped or Tshaped cross-section. A fourth stiffener section shape regularly used in ship-building is that of an extruded offset bulb plate (OBP). Structural idealisation of such arrangements can be made in a number of different ways. The most fundamental manner is discretisation into component parts of separate plates and stiffeners, known as plate-stiffener separation model [14]. Increasing the size of the structural units the structure can be modelled as an assembly of plate-stiffener combination units (plate-stiffener combination model [14]), which could be further increased in size to an assembly of stiffened panel units. The final idealisation method is by orthotropic plate approach, modelling the stiffened plate or panel as a thick plate with different stiffness in each orthogonal direction [14]. For ship structural analysis, plate-stiffener combination model is the predominant model chosen for the idealisation and for damaged structure [10]. Where the influence of damage in a structure and the conveyance of loads between the remaining plate and stiffener is to be modelled, plate-stiffener combination model is the most suitable idealisation to be adopted. For this reason only the platestiffener combination model has been used within the structural modelling in this paper.

The structural response of the idealised units is stored in the form of stress-strain curves for both tensile and compressive loading from zero load, through plastic yielding to failure or collapse, which are calculated analytically or by FEA in advance of any ISUM assessment. If assessing the stiffened panel collapse strength analytically, the effective width of plate flange must be correctly assessed. Alternatively, if assessing by FEA, suitable element type and size must be used to accurately calculate the membrane stresses in the arrangement, capturing the effective width of the plate, and the stress distribution in the stiffener web. 


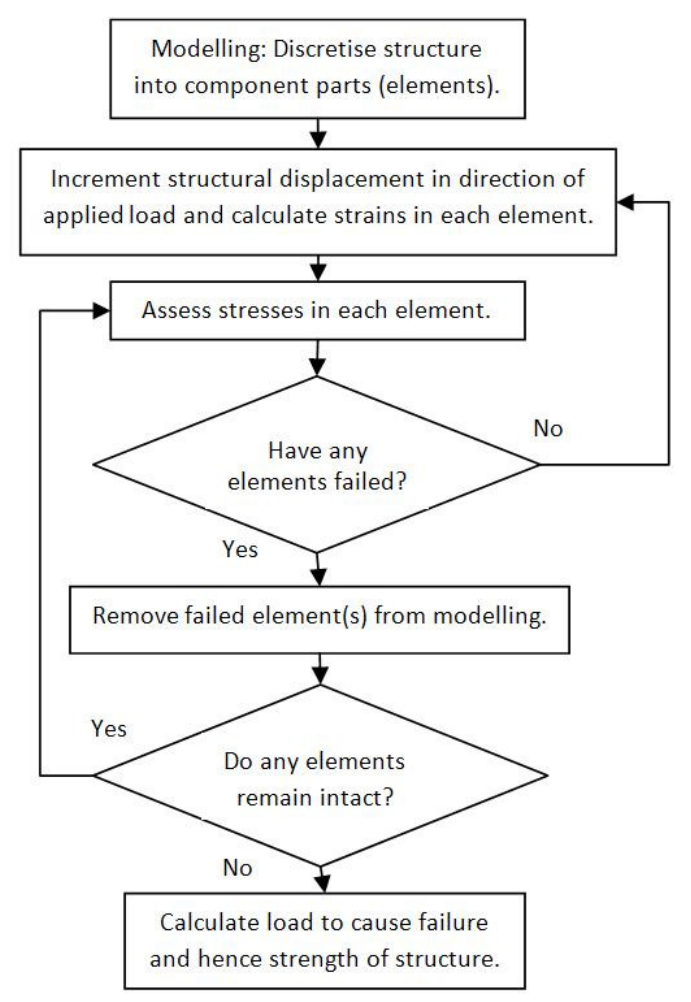

Figure 1 - ISUM application flow diagram

The method of assessment by ISUM, as shown by Figure 1, is undertaken by incrementally increasing the assumed structural deformation due to the applied loads, from which the strains in each of the structural units can be calculated and assessed against the pre calculated stress-strain curves. For assessment of overall collapse, by progressive collapse ISUM, on failure of a unit it is removed from the analysis and the iteration continued until the overall ultimate collapse strength of the structure is calculated.

The ISUM method has been applied to the assessment of damaged ship and offshore structures and shown to provide reasonable results when compared to FEA [16, 17]. However, it is believed that the assumptions required to apply ISUM in its current form to a damaged structure, results in a pessimistic assessment of the residual strength of the structure. As a stress-strain curve is required to be pre-calculated for each ISUM element arrangement in the structure, curves are only produced for intact ISUM elements and do not include damage due to the large number of curves that would be required to develop a library of curves for all the possible permutations. Therefore, to model a damage scenario, all damaged or partially damaged structural units are required to be removed from the model prior to commencing the analysis. 

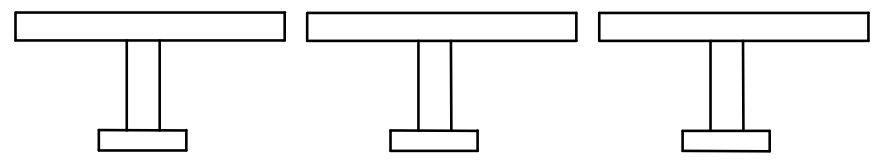

(a) Intact Panel

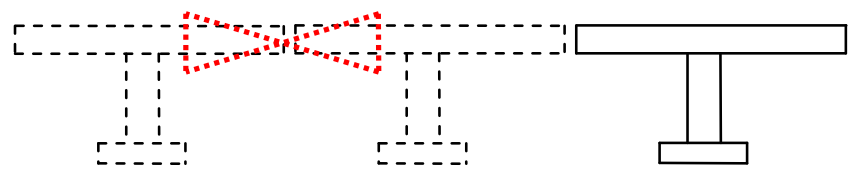

(b) Panel with damage to plate between two stiffeners, dashed panels removed due to damage at marked location.

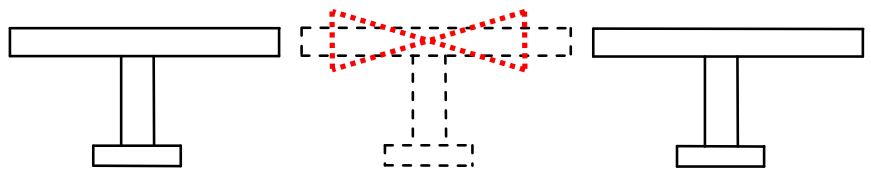

(c) Panel with damage to plate and central stiffener, dashed panel removed due to damage at marked location.

Figure 2 - ISUM approximation of a stiffened panel with three stiffeners - cross-section For example, in the case of an intact stiffened panel containing three attached stiffeners, the ISUM plate-stiffener combination idealisation, is that of the sum of three individual plate-stiffener elements as shown in Figure 2(a). Introducing damage to the same panel at a location between two stiffeners, though not damaging any stiffeners, the ISUM approximation is reduced to that of a single intact element, as shown in Figure 2(b). This assumption has to be made as the ISUM utilising stress-strain curves cannot account for damage in the elements. Introducing damage to the panel, located such that it damages a stiffener, the ISUM approximation is reduced to that of two intact elements as shown in Figure 2(c). As can be seen from this example, the modelling of damaged structures is simplified, and can be represented by the formulation in equation (1), where ' $\mathrm{P}_{\mathrm{u} 0}$ ' is the ultimate collapse load of the structure, ' $\mathrm{P}_{\mathrm{ui}}$ ' is the collapse load of the intact ISUM elements (obtained from the pre-calculated FEA stress-strain data) and ' $n$ ' is the number of intact ISUM elements. It is likely that formulation in this form will result in an overly pessimistic assessment of the residual strength of the structure by not accounting for the strength of the damaged elements.

$$
P_{u 0}=\sum_{i=1}^{n} P_{u i}
$$




\subsection{New ISUM for Damaged Structural Assessment}

In order to be able to benefit from the rapid modelling capability of ISUM, but be able to capture the damage to a stiffened panel and hence more accurately model the total structure, it is proposed that additional information is captured in relation to the collapse strength of the damaged panels and included in the formulation. This is achieved by modifying equation (1) to include the damaged panel strength, as shown in equation (2), where ' $\mathrm{P}_{\mathrm{ud}}$ ' is the collapse load of the damaged ISUM units (obtained from pre-calculated FEA data) and ' $m$ ' is the number of damaged ISUM elements.

$$
P_{u 0}=\sum_{i=1}^{n} P_{u i}+\sum_{d=1}^{m} P_{u d}
$$

To do this, additional structural data is required to be generated and stored for use by the method in relation to the residual strength of the damaged structural ISUM elements.

\subsection{ISUM Element Assessment by Finite Element Method}

In order to investigate the applicability of ISUM to the collapse analysis of damaged steel-plated structures, Finite Element Method (FEM) was chosen as the preferred analysis tool for pre-assessment of the collapse strength of the elements (' $\mathrm{P}_{\mathrm{ui}}$ ' and ' $\mathrm{P}_{\mathrm{ud}}$ ' in Equation (2)) used in the ISUM assessment. FEA is a method that allows accurate modelling of complex structural problems, particularly where non-linear material properties and geometrical characteristics are to be assessed. It is also an effective method to undertake the analysis of a large number of structural models of the sizes required by this assessment, due to the ability to automate much of the modelling process. For this study, the FEA was undertaken using the commercial FEA software ANSYS.

Modelling of the plate-stiffener combinations has been undertaken by utilising discrete plate approach, in order to model the combinations as part of a much larger stiffened panel arrangement. Each panel is subjected to both out-of-plane lateral and in-plane axial compressive loading to assess the affect of damage variations on the collapse load of the panel and account for lateral loadings that 
could be present from, for example, vehicle, cargo or hydrostatic pressure loads. To simulate this, in each case the lateral load is applied in full prior to incremental application of the axial load.

The ANSYS model was created using a four noded quadrilateral isoparametric linear shell element (SHELL181), to model both the plate and stiffener, with the triangular form of the element used as a filler element around the damage aperture where applicable. This element is suitable for undertaking the analysis of linear, large-rotation and large strain non-linear plates including membrane stiffness and thus suitable for this study. The element itself has six degrees of freedom at each node (UX, UY, UZ, ROTX, ROTY, ROTZ). Material non-linearities are accounted for using a bilinear isotropic rate independent hardening with von Mises yield criteria assuming an elasto-perfectly plastic stress strain relationship.

The model is constrained by simply supported boundary conditions along the loaded and reactive edges, to calculate the lowest collapse load of each panel arrangement. Rotation about the longitudinal direction is constrained at all nodes along the longitudinal edges with the displacement along the same edges allowed to freely wave in, allowing for continuity between adjacent stiffened plates. To ensure uniform compression of the loaded edge, a coupled constraint equation is applied to the loaded edge before the load is applied incrementally. If the damage removes any structure along the unloaded edges, no boundary condition is applied in the region of the damage. Figure 3 shows an example meshed stiffened-plate model and applied boundary conditions.

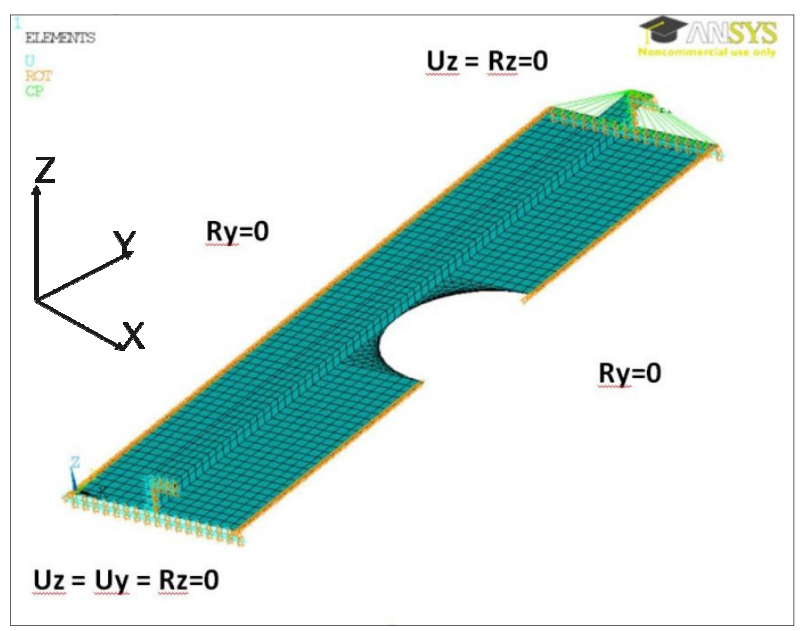

Figure 3 - Meshed Panel and Applied Boundary Conditions 


\subsection{Finite Element Verification}

Modelling of the stiffened panels was undertaken utilising a finite element model developed and verified during previous work by the authors. Full verification of the model is published in Underwood et al. [18], drawing on work presented by Suneel Kumar et al. [19]; therefore, full details of the verification of the model has not been included in this paper. However, Figure 4 shows results of the calculated collapse strength of the developed model and those from the model developed by Suneel Kumar et al [19] results, demonstrating the correlation between the models. The results plot plate slenderness ratio, ' $\beta$ ' (3) against normalised axial load $\left(\mathrm{P}_{\mathrm{u} 0} / \mathrm{P}_{\mathrm{sq}}\right)$ for different column slenderness ratios ' $\lambda$ ' (4). Where $P_{s q}$ is the compressive "squash" load, defined as the summation of the product of the cross-sectional area of the plate and the yield stress of the plate with the product of the crosssectional area of the stiffener with the yield stress of the stiffener. It should be noted that the slenderness ratio is calculated based on the intact geometrical arrangement and no attempt has been made to calculate a damaged slenderness ratio using an effective damaged breadth.

$$
\begin{aligned}
& \beta=\frac{b}{t} \sqrt{\frac{\sigma_{y}}{E}} \\
& \lambda=\frac{L}{r \pi} \sqrt{\frac{\sigma_{y}}{E}}
\end{aligned}
$$

In the above relationships, ' $\sigma_{\mathrm{y}}$ ' is the Yield Stress of the material, 'E' is the Young's Modulus, 'b' is the panel breadth or stiffener spacing , ' $\mathrm{t}$ ' is the plate thickness, ' $\mathrm{L}$ ' is the panel length and ' $\mathrm{r}$ ' is the radius of gyration calculated based on the effective breadth of attached plate.

Verification of the model in conjunction with the convergence study undertaken by Suneel Kumar et al. [19], confirmed that regular quadrilateral elements with element edge length of $25 \mathrm{~mm}$ were suitable for meshing areas within the plate and stiffener, with triangular elements used to mesh the area around the damage aperture. 


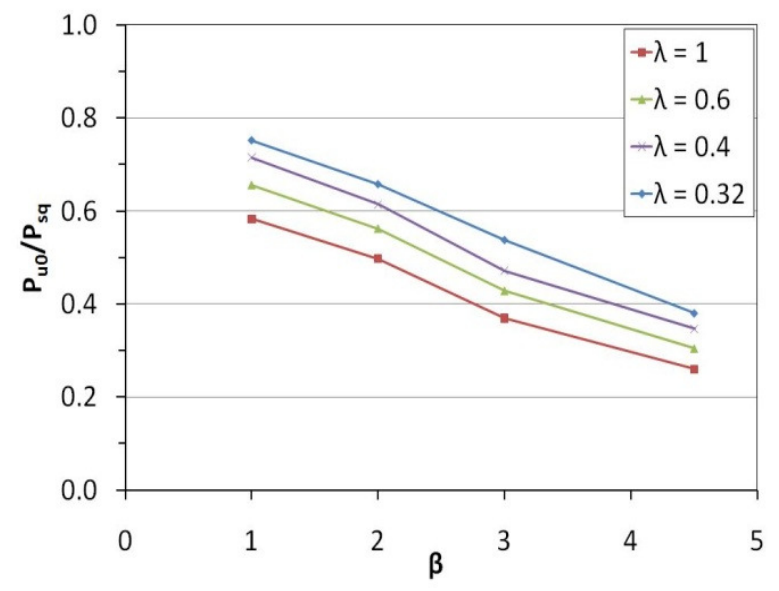

Figure 4 (a)

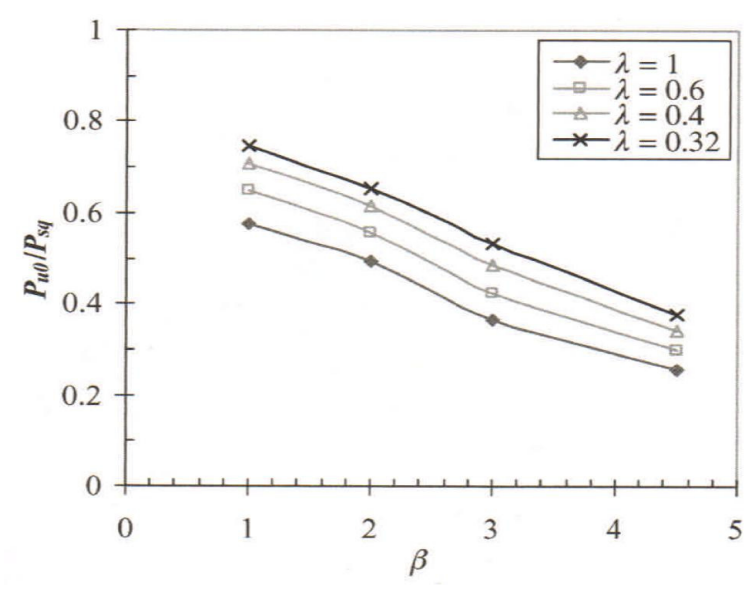

Figure 4 (b)

Figure 4 - Effect of Plate $(\beta)$ and Column $(\lambda)$ Slenderness Ratios on Normalised Axial Load (a)Verification and (b) Suneel Kumar et al. [19] Results

\section{Results}

\subsection{Overview}

Using the verified stiffened-panel FEA model to calculate the ISUM element data (' $\mathrm{P}_{\mathrm{ui}}$ ' and ' $\mathrm{P}_{\text {ud }}$ ' in Equations (1) and (2)), the study was undertaken to assess the application of ISUM to the assessment of damaged stiffened panels, the application of the new ISUM and to determine the effect that variations in material properties, plate thickness, plate slenderness and damage size and shape have upon the panel's collapse strength.

This was done through three different arrangements; with the first model arrangement that of an intact stiffened panel. The second arrangement is a damaged stiffened panel where damage was located only in the plate itself and positioned with its centre halfway between two stiffeners (Figure 5). The third arrangement is a damaged panel where the damage location results in loss of a single stiffener by positioning the centre of the damage in line with the central stiffener of the panel. These idealised damage cases are shown in Figure 2. Analysis was run for both the complete stiffened panel (containing 3 stiffeners) by FEA and by ISUM following assessment of the required ISUM elements for each case by FEA.

Damage to the panels was simulated by removing areas of structure in the form of either a rectangular, elliptical or triangular form. An example of a damaged singularly stiffened panel and its 
equivalent multiple stiffened panel are shown in Figure 5(a) and Figure 5(b) respectively. In all cases, the attached stiffener profile was that of an Indian Standard Angle, ISA7045 6 of overall height of $70 \mathrm{~mm}$, flange breadth of $45 \mathrm{~mm}$ and $6 \mathrm{~mm}$ thickness for both flange and web, resulting in a column slenderness $(\lambda)$ of $0.61,0.66,0.67,0.68$ for plate slenderness $1,2,3$ and 4 respectively for the intact condition based on the mean values detailed in Table 1.

A number of simulations for each model arrangement were run to determine the effects of different variables. The combination of variables for each case were chosen using a Latin hypercube, based on a mean value and range of allowable values, as shown in Table 1 . Ranges were selected based on referenced literature and the likelihood of those values occurring in a real life situation. Whilst the damaged scenarios modelled are of an idealised nature, the selected configurations and distributions have been conceived to provide an irregular combination of variables, using the perceived worst case damage aperture shapes (of rectangle, ellipse or triangle), whilst maintaining a regular form.

For the configuration used, the overall collapse mode is through the development of a plastic hinge within the panel, influenced by the damage. To complete the study, a number of simulations were run using the different damage aperture shape to determine the effect of aperture shape upon the collapse strength.

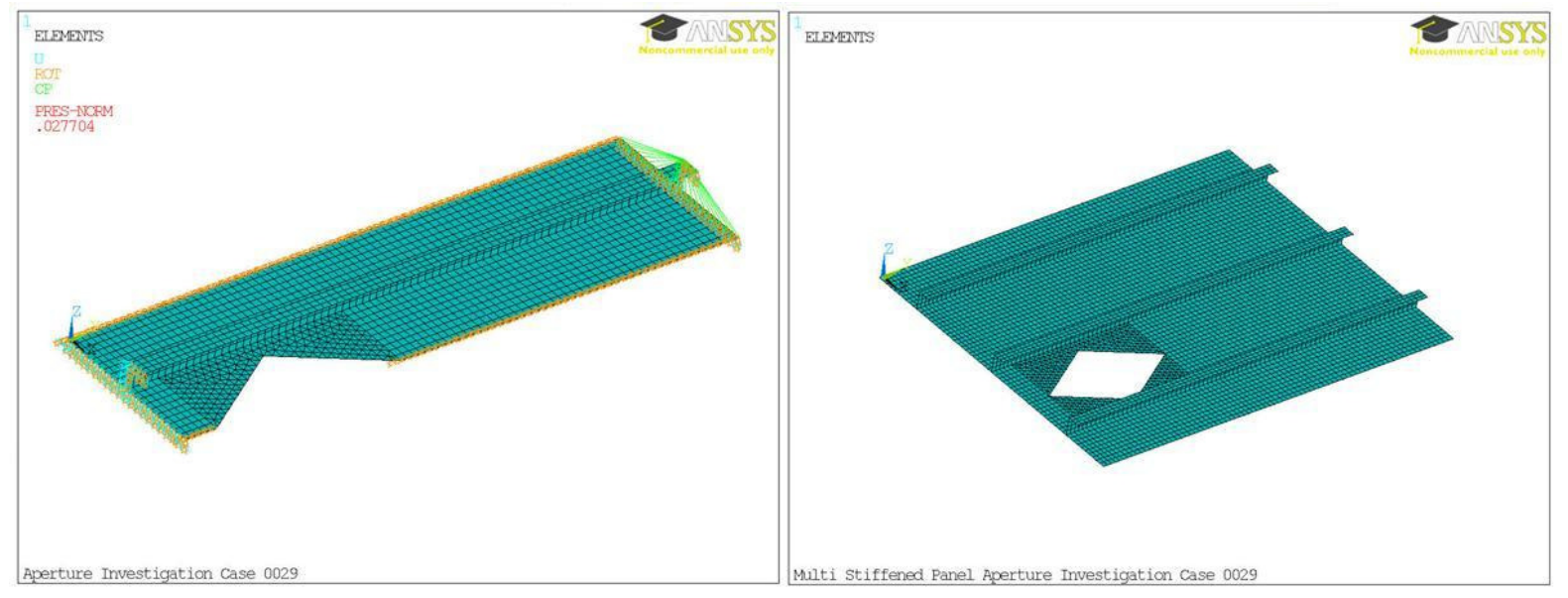

Figure 5 (a)

Figure 5 (b)

Figure 5 - Example case of damaged singular stiffened and equivalent multi-stiffener panels. 
Table 1: Panel Property Variation Values and Distribution

\begin{tabular}{|lc|c|c|}
\hline Property & $\begin{array}{c}\text { Mean } \\
\text { Value }\end{array}$ & Range \\
\hline Damage Breadth $(\mathrm{mm})$ & & 227 & $3-744$ \\
\hline Damage Position $(\mathrm{mm})$ & & 170 & $23-665$ \\
\hline Plate Thickness $(\mathrm{mm})$ & {$[20]$} & 6 & $5.93-6.07$ \\
\hline Lateral Load $\left(\mathrm{N} / \mathrm{mm}^{2}\right)$ & {$[20]$} & 0.035 & $0.021-0.0384$ \\
\hline Young's Modulus $\left(\mathrm{N} / \mathrm{mm}^{2}\right)$ & {$[21]$} & $2 \times 10^{5}$ & $196040-203960$ \\
\hline Yield Stress $\left(\mathrm{N} / \mathrm{mm}^{2}\right)$ & {$[21]$} & 250 & $232.68-267.33$ \\
\hline
\end{tabular}

The results for the different simulations are shown in Section 3.2 - Section 3.5, followed by an analysis of how the variation affected the failure. This allowed comparison to be made between the predictions that would be given by implementing ISUM to assess damage to those performed using FEA for a whole multiple stiffened panel.

The results of assessments have been presented by plotting plate slenderness ratio, ' $\beta$ ' (3) against normalised axial load $\left(\mathrm{P}_{\mathrm{u} 0} / \mathrm{P}_{\mathrm{sq}}\right)$. It should be noted that the plate slenderness ratio is calculated based on the intact geometrical arrangement and no attempt has been made to calculate a damaged slenderness ratio using an effective damaged breadth.

\subsection{Intact Plate ISUM Analysis}

The verified model of a single stiffened plate was used to calculate the failure load of 100 stiffened panel arrangements for a combination of randomly generated variables within the ranges detailed in Table 1. This was undertaken for both a plate and single stiffener arrangement and equivalent plate with three stiffeners. This analysis allowed a comparison between the cases where the model was approximated by combining the failure load of three single stiffened panels, as per ISUM, with the results of the equivalent three stiffened panel. The normalised axial failure load could then be compared to the slenderness ratio, where Figure 6 shows the results for the ISUM single stiffener arrangement and Figure 7 shows the results for the multiple stiffened panel arrangement. The results from this analysis show that there is a low variability in the resulting failure load for the different input variables. This variability is smaller at a low slenderness ratio and grows larger as the 
slenderness ratio increases. It can also be seen that there is a high similarity between the results in this analysis. This produces a difference of $4.7 \%$ for the normalised failure load with a range of 0 $10 \%$, showing that the single stiffened panel is a good approximation to the multiple stiffened panel for the intact case and that the ISUM is always conservative in its prediction of collapse strength of an intact panel.

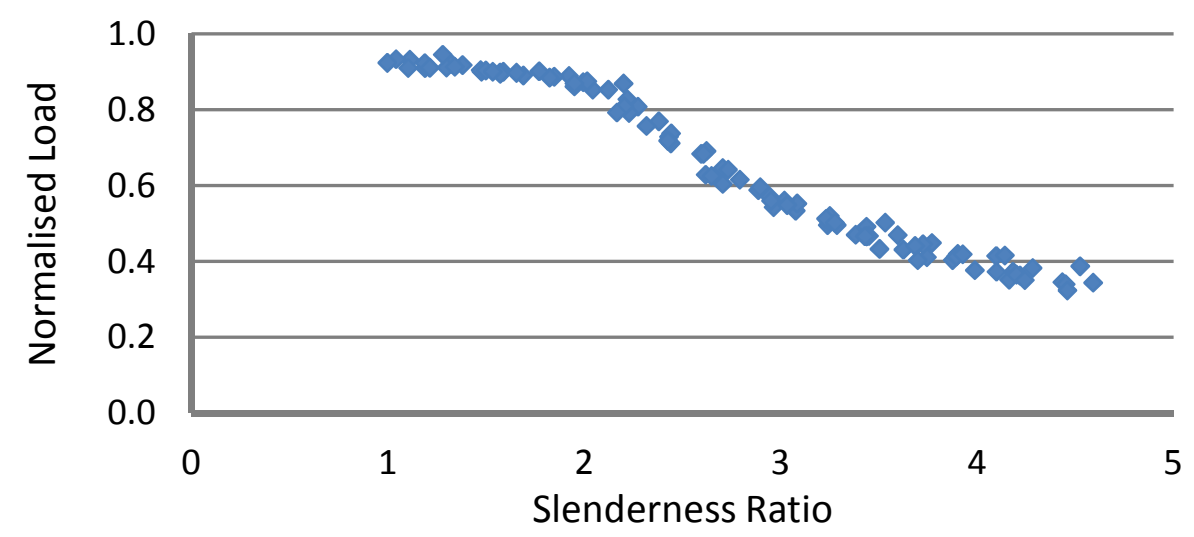

Figure 6 - Normalised Axial Failure Load for Intact panel against Slenderness Ratio (Single Stiffener ISUM)

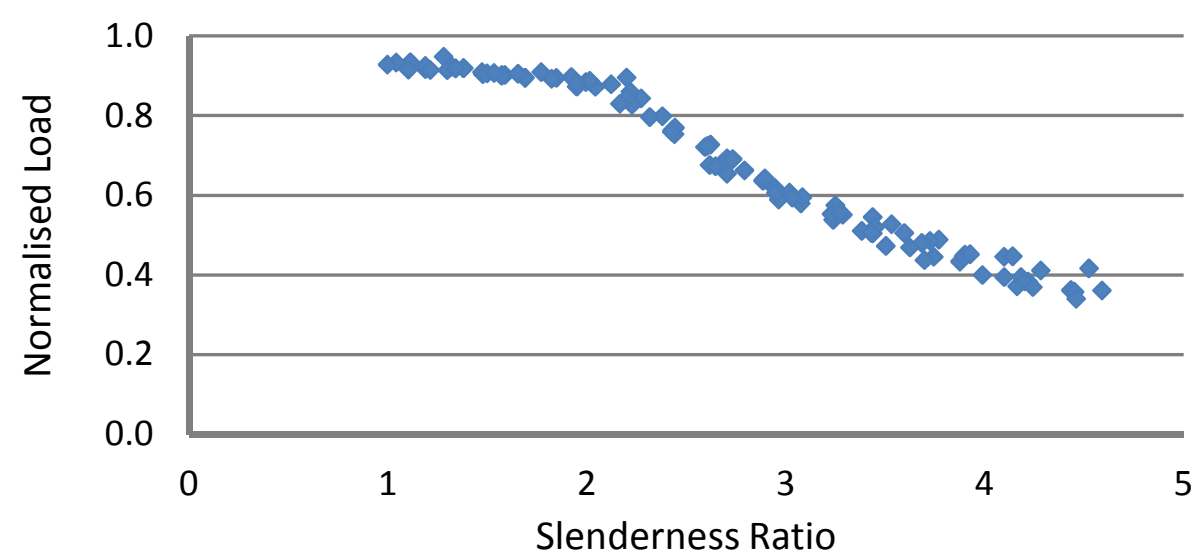

Figure 7 - Normalised Axial Failure Load for Intact Panel against Slenderness Ratio (Multiple Stiffened Panel)

\subsection{Damaged Plate ISUM Analysis - Plate Damage Only}

Investigating the effects of damage to the plate between stiffeners, the same set of 100 cases were run, though incorporating damage such that the centre of the damage is located at the midpoint between stiffeners ensuring neither adjacent stiffener is damaged, as per the example in Figure $5 b$. 
Implementing ISUM for assessing damage in this configuration, the multiple stiffened panel consisting of three stiffeners is reduced to a single intact stiffened panel, as shown in Figure $2 \mathrm{~b}$. As would be expected for this arrangement, the resulting plot followed a similar trend pattern for the failure load in comparison with the slenderness ratio to the intact state, Figure 8 compared to Figure 6. However, it can be seen for these results that the failure load is much lower than for the other cases. This is because it is assumed that two of the stiffeners are removed as there is damage around this area.

Implementing the new ISUM for the case of the combined single stiffener with damaged plate, for which the results are shown in Figure 9; here the plate is reduced to the assumed approximation of one intact single stiffened panel combined with two damaged single stiffened panels, which is far more representative of the case being modelled. It can be seen in Figure 9 that the failure load is much higher than for the original ISUM case. The variability on this plate was larger than for the intact situation. These results were then reproduced for the multi stiffened panel model, the results for which are shown in Figure 10.

The results again followed a similar pattern to that produced for the intact panel but with again a larger amount of variation. Finally it was possible to compare the difference between the multiple stiffener model and the ISUM model, the results of which are shown in Figure 11. Due to the nature of the ISUM treating any failure in the plate with removal of the adjacent stiffener, it can be seen that this method results in a large difference between the two methods. The range of the difference between the two methods was $55 \%-70 \%$ with a mean value of $65 \%$. This result is expected, as the assumed arrangement removes $2 / 3^{\text {rds }}$ of the structure; however, it demonstrates the conservative nature of the method when applied to damaged structure. 


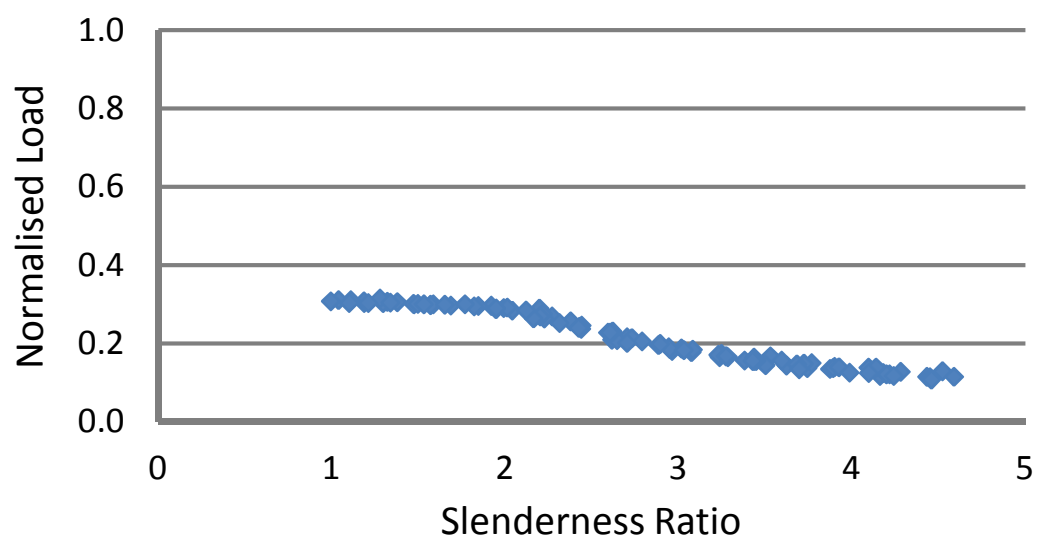

Figure 8 - Normalised Axial Failure Load against Slenderness Ratio for Panel with Plate Damage Only (Single Stiffener ISUM)

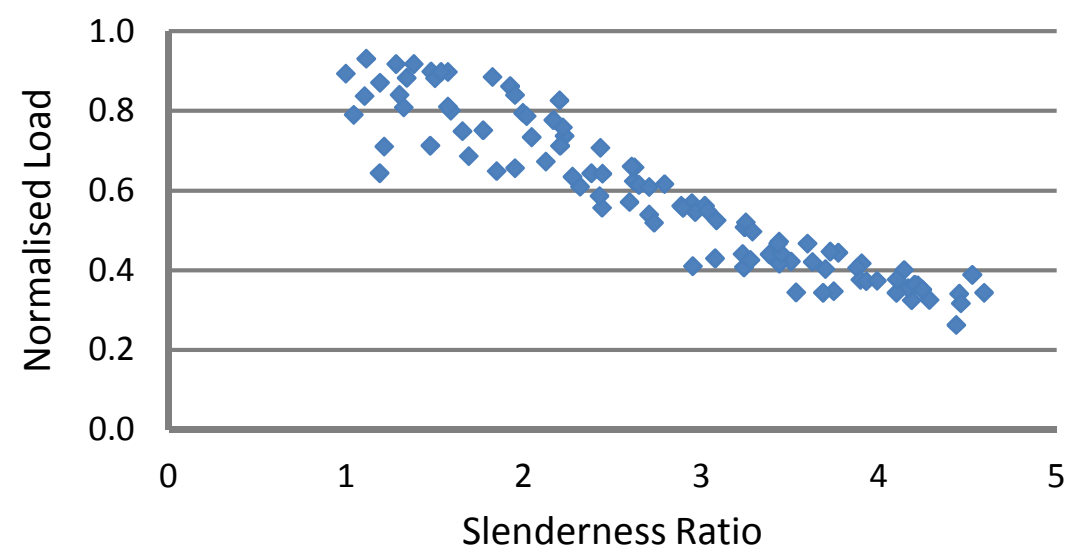

Figure 9 - Normalised Axial Failure Load against Slenderness Ratio for Panel with Plate Damage Only (New ISUM)

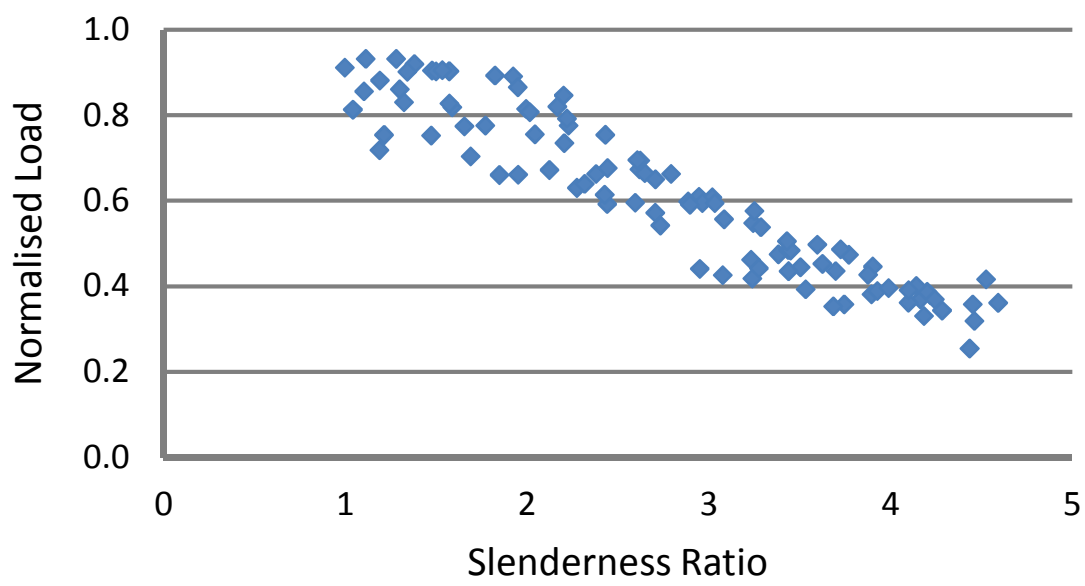

Figure 10 - Normalised Axial Failure Load against Slenderness Ratio for Panel with Plate Damage Only (Multiple Stiffened Panel) 


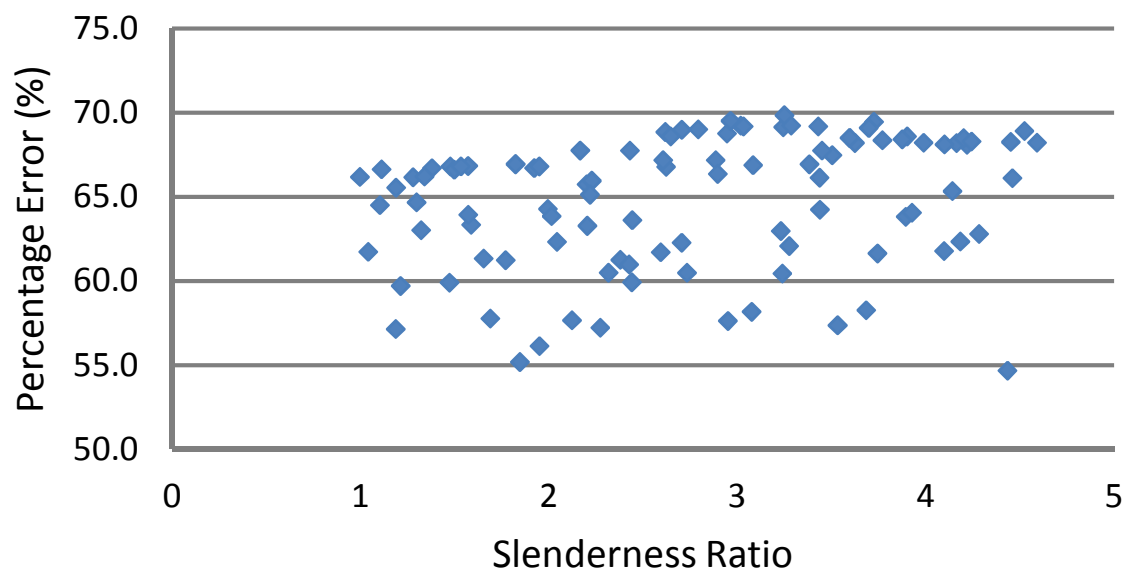

Figure 11 - Percentage Difference Between Multiple Stiffener Model and ISUM (Plate Damage Only)

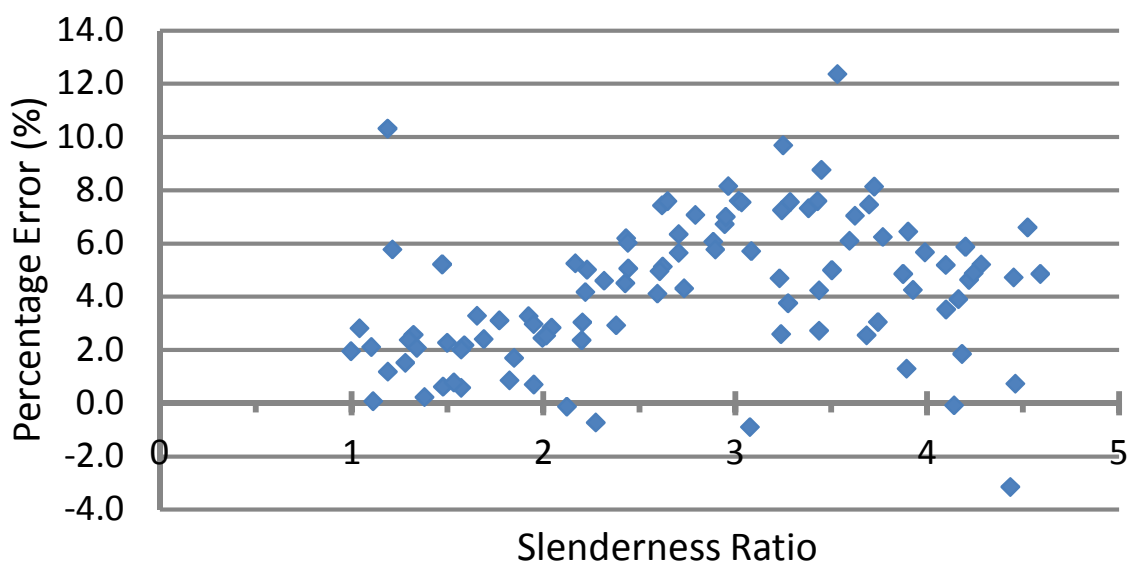

Figure 12 - Percentage Difference Between Multiple Stiffener Model and New ISUM Incorporating Damage (Plate Damage Only)

For the proposed new ISUM, it is possible to do a similar comparison to the multiple stiffened panel arrangement. The results can be seen in Figure 12, where the range for these results was between $3.1 \%$ and $12.4 \%$ with the mean error being $4.33 \%$. From the one hundred panel arrangements, only five results had a negative value. This shows that for a local stress analysis in situations where the stiffener was not damaged the new ISUM method gave a reasonable level of accuracy when compared to the FEA. It also shows that the new ISUM in general gave a conservative estimate, though less conservative than the original ISUM. In the cases where there was a non-conservative estimate, the error was on average less than $1 \%$. 


\subsection{Damaged Panel ISUM Analysis - Plate and Stiffener Damage}

Having determined the results for the event where only the plate was damaged, a set of results were run for the event where the stiffeners themselves are damaged. The same set of 100 cases were generated, repositioning the centre of the damage in-line with the central stiffener of the three stiffener panel.

The results for the ISUM arrangement can be seen in Figure 13, where the panel is reduced to two intact panels as shown in Figure 2. The results for this analysis have a low variability at low slenderness ratio but at higher slenderness ratios show variability up to 0.1 , caused by the included variation in material properties and plate thickness within the cases. The equivalent multi stiffener panel cases were also run, with results shown in Figure 15. For these results it is possible to see that the variability of these scenarios is higher than for the intact panel cases and also higher than the case where the damage was only in the plate itself. A comparison between the multiple stiffener panel and that of the ISUM showed that there was a difference between the results as seen in Figure 16. This ranged in the region of -5.8 to $36.2 \%$ with a mean value of $10.7 \%$. This shows that the difference between this analysis and the ISUM is closer than for the damaged plate scenario. This result is unsurprising as the ISUM works by removing damaged elements; hence $1 / 3^{\text {rd }}$ of the panel is removed. However, it can be seen that even though the average difference between the methods is low, $10.7 \%$, some of the errors can be much higher, $36.2 \%$.

Implementing the new ISUM, the results for which are shown in Figure 14, the panel is reduced to the approximation of two intact elements and the single damaged element. The correlation between the new ISUM results and the full panel results are shown in Figure 17, where it can be seen that the new ISUM results are much closer to the full panel FEA results.

It should also be noted that a small number of the percentage differences were negative, showing that the ISUM method is not always conservative. This has been shown to be due to different deflection mode shapes appearing in the undamaged sections of the full three stiffened panel arrangement, which the ISUM is unable to assess due to the physical separation of its constituent parts. 


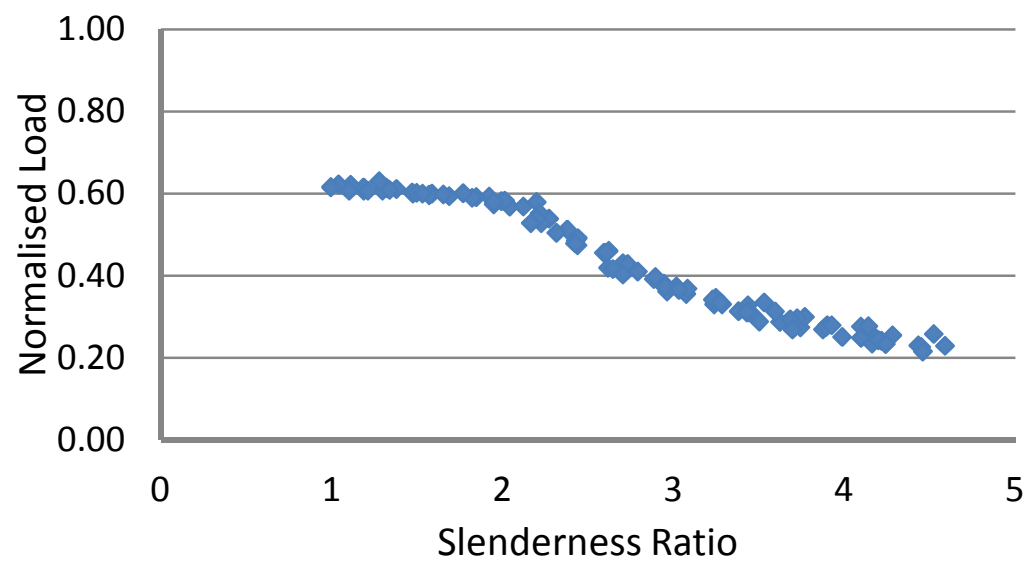

Figure 13 - Normalised Axial Failure Load of Stiffener Damaged Model against Slenderness Ratio (Single Stiffener ISUM)

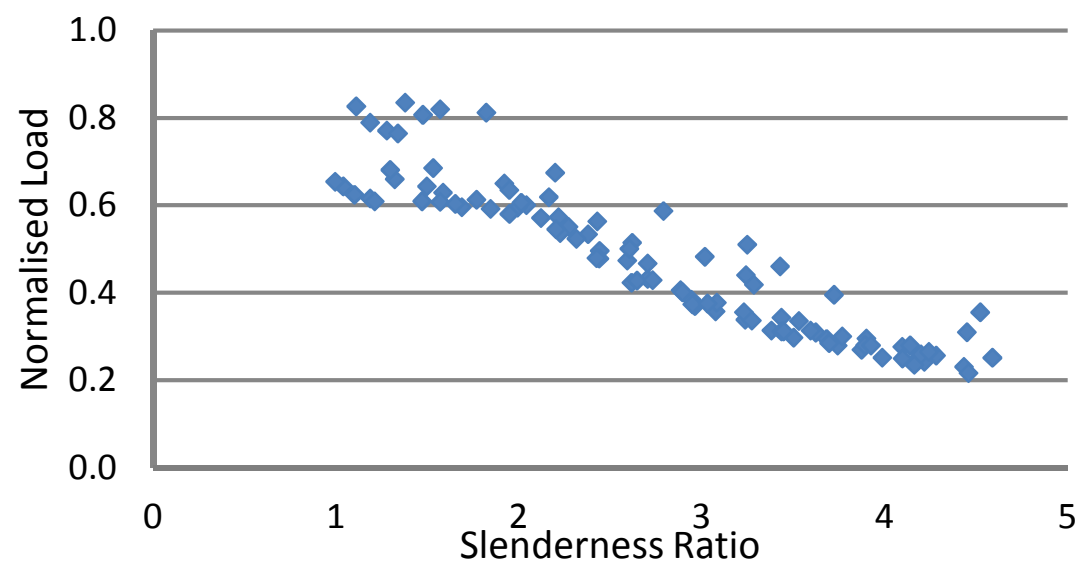

Figure 14 - Normalised Axial Failure Load of Stiffener Damaged Model against Slenderness Ratio (New ISUM)

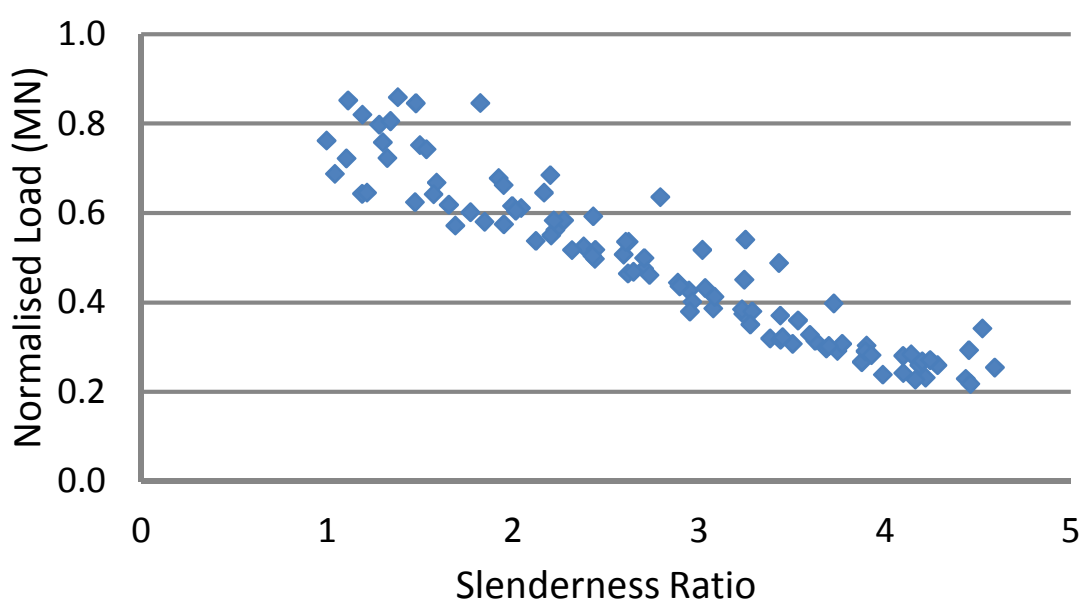

Figure 15 - Normalised Axial Failure Load of Stiffener Damaged Model against Slenderness Ratio (Multiple Stiffened Panel) 


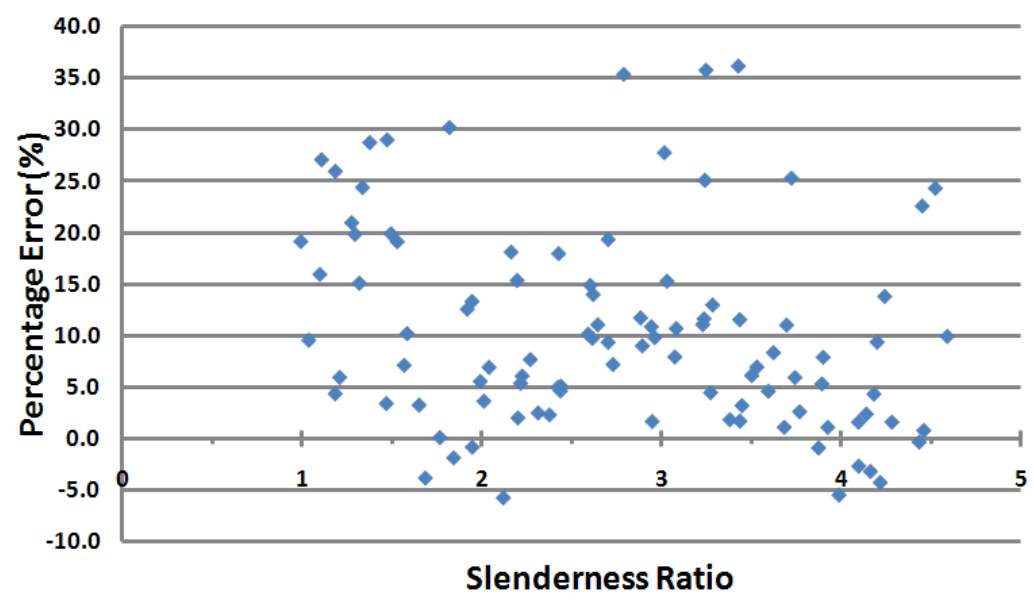

Figure 16 - Percentage Difference Between Multiple Stiffener Model and ISUM (Stiffener Damage)

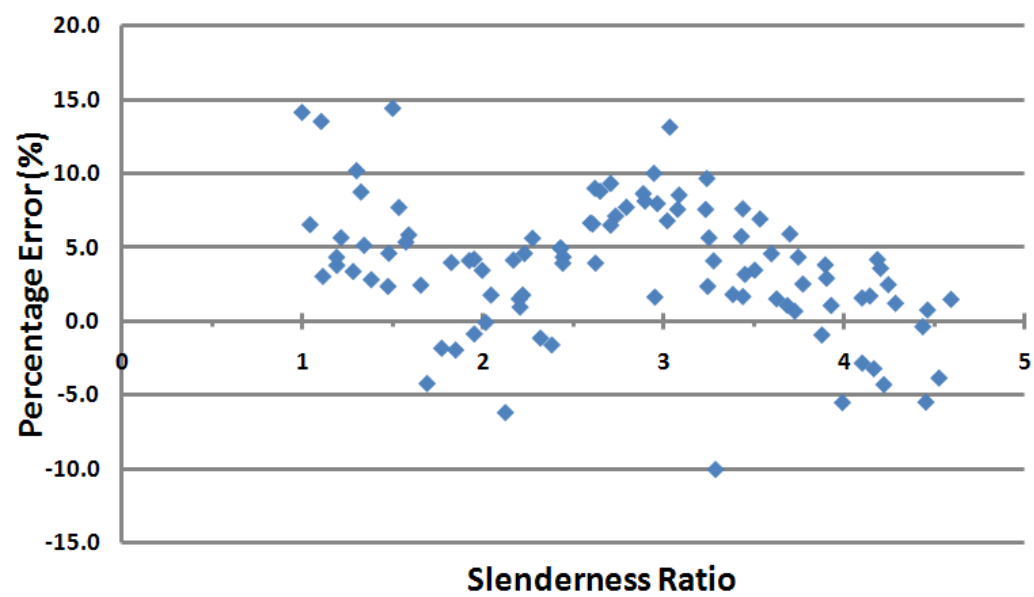

Figure 17 - Percentage Difference Between Multiple Stiffener Model and New ISUM (Stiffener Damage)

\subsection{Assessment of the Effects of Damage Area and Shape on Ultimate Collapse Strength}

From the results of the intact panel cases, it can be seen that the variation due to changes in material properties and plate thicknesses is low. Therefore, it has been assumed that the variation seen between two damage events arise from the damage itself.

To investigate the effect of damage size in relation to the overall panel plate area, sets of 70 damage events were run for four panel arrangements of different slenderness ratio. The set size was determined to allow suitable incrementation of the damage aperture to produce sufficient results for the analysis. The stiffener profile is retained as ISA7045 6, plate thickness maintained as $6 \mathrm{~mm}$ and 
material properties fixed with a yield stress of 250MPa, Young's Modulus of $2 \times 10^{5} \mathrm{MPa}$ and Poisson's Ratio of 0.3 . The events were configured to either damage the plate only or to damage both plate and central stiffener of a three stiffened panel arrangement and were run for diamond, elliptical and rectangular damage aperture, extending the length of the aperture to equal the panel length, and breadth to the applicable stiffener spacing dimension. In each case a lateral load of $0.03 \mathrm{MPa}$ is applied in full prior to the application of the axial compressive load to collapse. The lateral load applied develops a small initial deflection in the panel, which for the intact panel equates to a maximum deflection of $0.46 \mathrm{~mm}, 1.16 \mathrm{~mm}, 3.03 \mathrm{~mm}$ and $7.0 \mathrm{~mm}$ for the panels of plate slenderness ratio $1,2,3$ and 4 respectively.

From the results in Figure 18, Figure 19 and Figure 20 it can be seen that for the case where only the plate of the three stiffener panel is damaged, as the ratio of damage area to overall plate area increases the failure load of the panel reduces from the intact panel strength at an almost linear rate. This compares to the results for the case where the central stiffener of the three stiffener panel is damaged, Figure 21 to Figure 23, where there is an initial rapid decline in panel strength as the central stiffener is severed by the damage, before again the strength reduces to an almost linear rate of decline as the damage area ratio increases. The damage area ratio has been calculated as the ratio of area of plate removed to the area of plate for the intact panel.

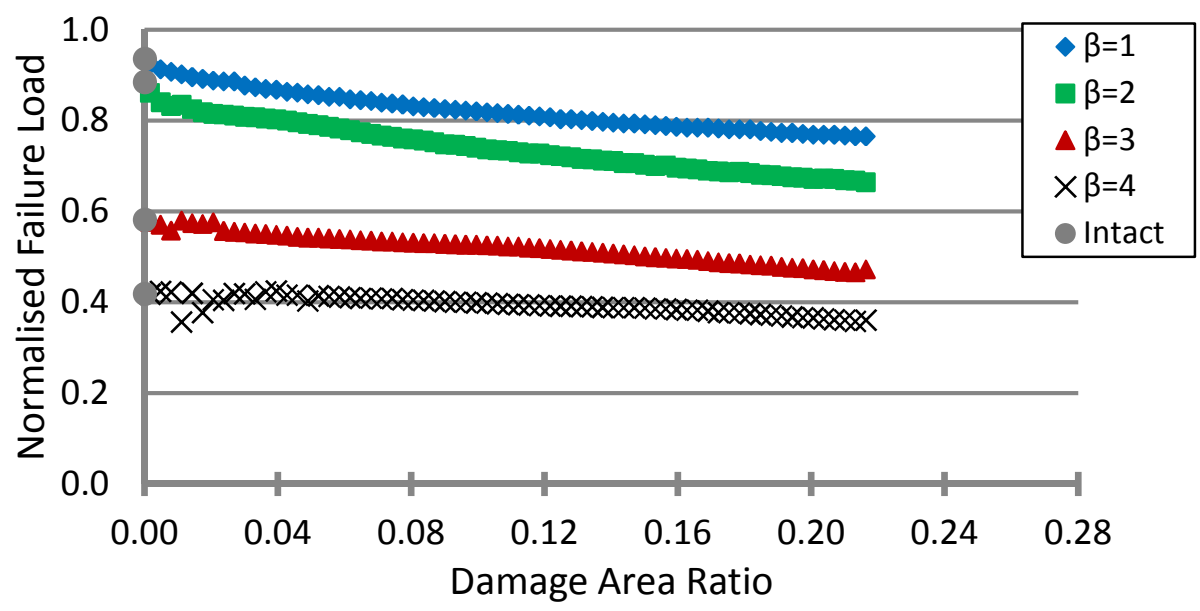

Figure 18 - Normalised Axial Failure Load Against Area Ratio for Plate Damage Only Diamond Aperture 


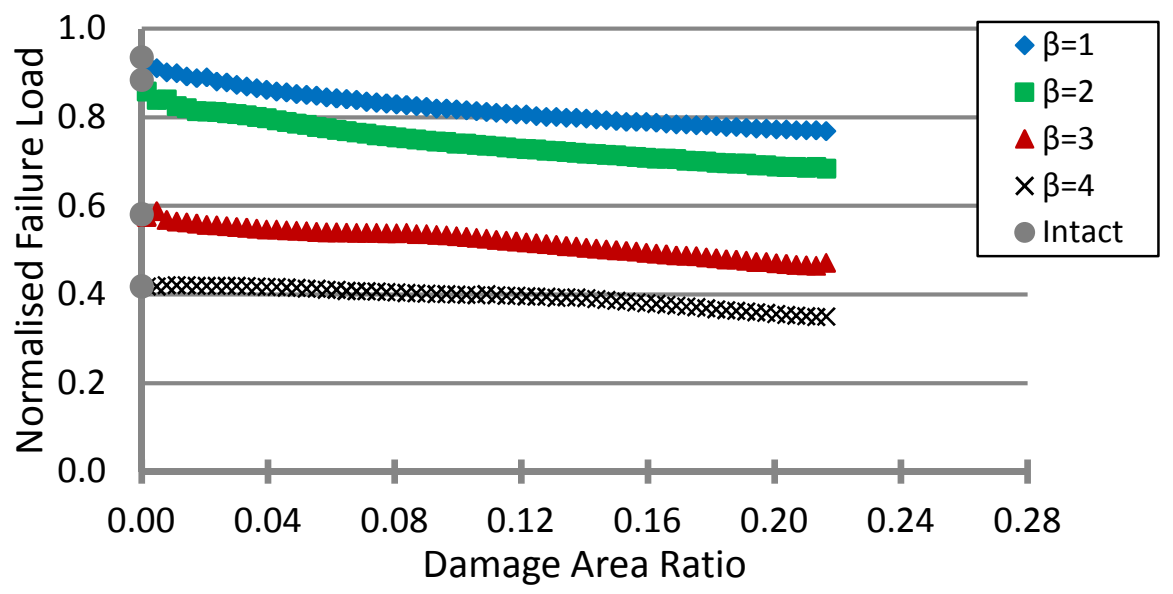

Figure 19 - Normalised Axial Failure Load Against Area Ratio for Plate Damage Only Ellipse

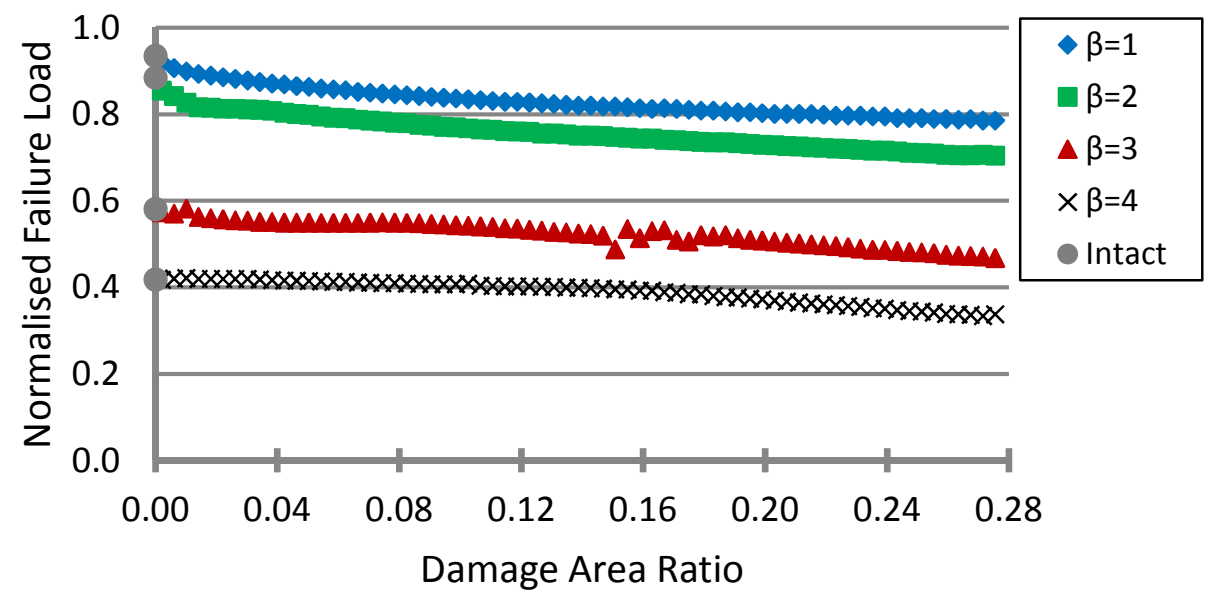

Figure 20 - Normalised Axial Failure Load Against Area Ratio for Plate Damage Only Square Aperture

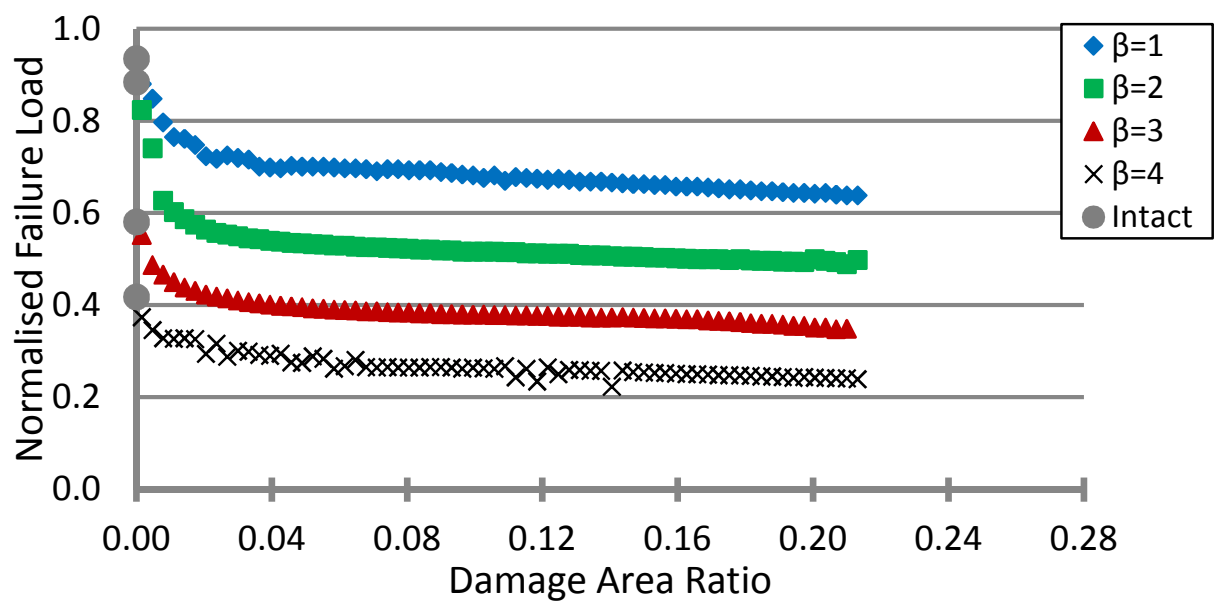

Figure 21 - Normalised Axial Failure Load Against Area Ratio for Plate and Stiffener Damage - Diamond Aperture 


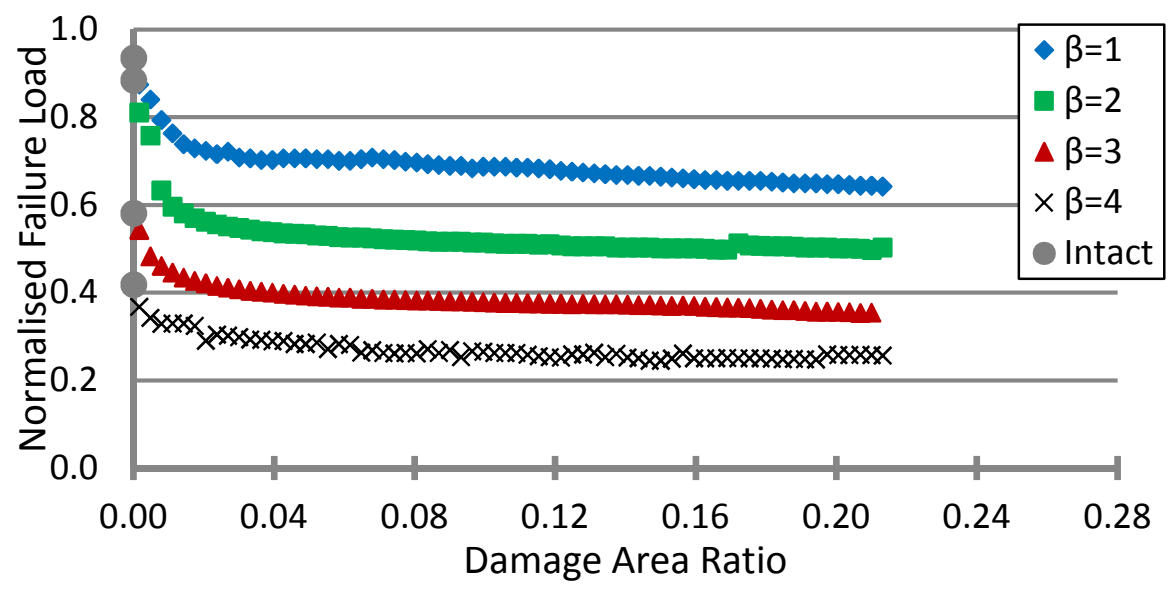

Figure 22 - Normalised Axial Failure Load Against Area Ratio for Plate and Stiffener Damage - Ellipse Aperture

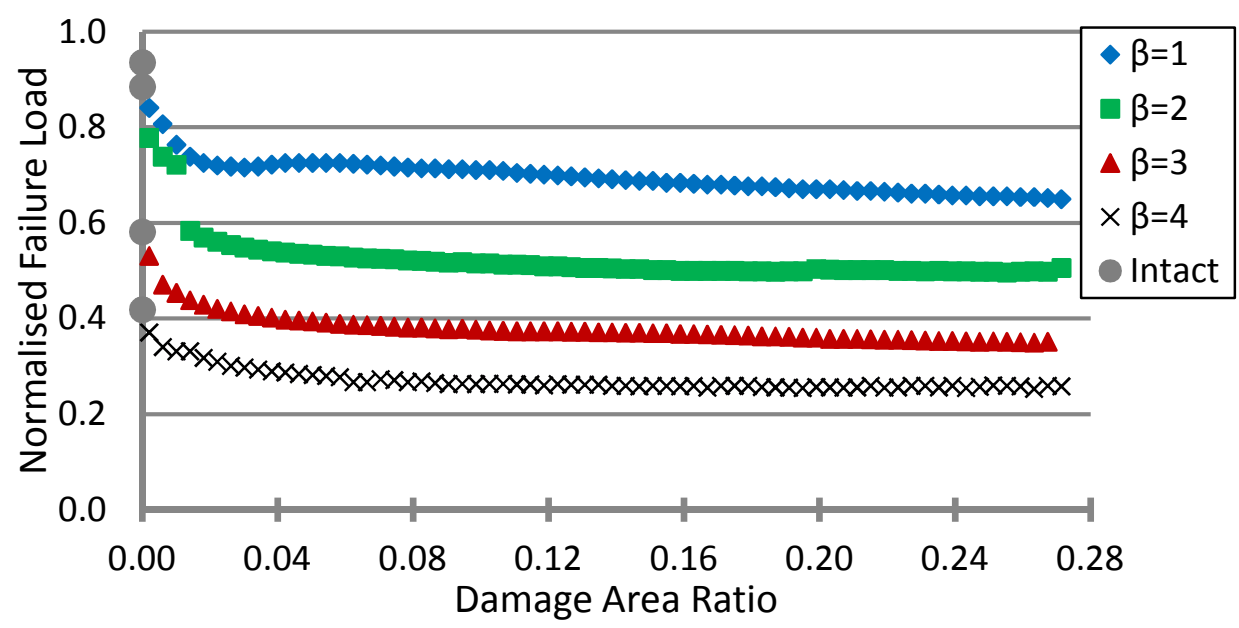

Figure 23 - Normalised Axial Failure Load Against Area Ratio for Plate and Stiffener Damage - Square Aperture

As can be seen from Figure 18 to Figure 23 and in Table 2, the effect of different damage aperture shapes on the normalised failure load for the panels for a given area ratio is minimal, with the mean difference shown to be less than $2 \%$ for all slenderness ratios assessed.

Table 2: Variation in Normalised Failure Load for Different Damage Aperture Shapes

\begin{tabular}{|c|c|c|}
\hline Slenderness Ratio & $\begin{array}{c}\text { Mean \% Difference } \\
\text { Failure Load Plate } \\
\text { Damage Only }\end{array}$ & $\begin{array}{c}\text { Mean \% Difference } \\
\text { Failure Load Plate } \\
\text { and Stiffener Damage }\end{array}$ \\
\hline 1 & -0.13 & -0.31 \\
\hline 2 & -0.96 & +0.90 \\
\hline 3 & +0.33 & +1.83 \\
\hline 4 & +1.92 & -0.14 \\
\hline
\end{tabular}


Analysis was performed to determine how the different aperture shapes affected the failure load the multi stiffened plates, Table 3 show that there is a low variation for the three different shapes that have been chosen. This was slightly offset by the maximum variation that could occur. The results show that the square shape and the diamond shape had a larger variation from the mean than the elliptical shapes. The largest variation from the mean was $32 \%$ failure load for the square shaped damage. These maximum variations can be seen to occur in the results above, for example in Figure 20 for a slenderness ratio of 3 an area of variation occurs in the trend for area ratio of $0.15-0.18$, where fluctuations in the decline of the normalised failure load can clearly be seen as area ratio increases. This anomaly was noted in Section 3.4 and again has been shown to be due to the formation of different deflection modes in the undamaged plate between of the multi-stiffened panel for these specific damage configurations, an example of which is shown in Figure 24.

Table 3: Absolute Variation of Failure Load from the Mean for Different Damage Aperture Shape

\begin{tabular}{|l|c|c|}
\hline \multirow{2}{*}{} & \multicolumn{2}{|c|}{ Failure Load } \\
\cline { 2 - 3 } & $\begin{array}{c}\text { Mean } \\
\text { Variation }\end{array}$ & $\begin{array}{c}\text { Maximum } \\
\text { Variation }\end{array}$ \\
\hline Diamond & $3.4 \%$ & $32 \%$ \\
\hline Square & $3.4 \%$ & $25 \%$ \\
\hline Ellipse & $1.3 \%$ & $27 \%$ \\
\hline
\end{tabular}

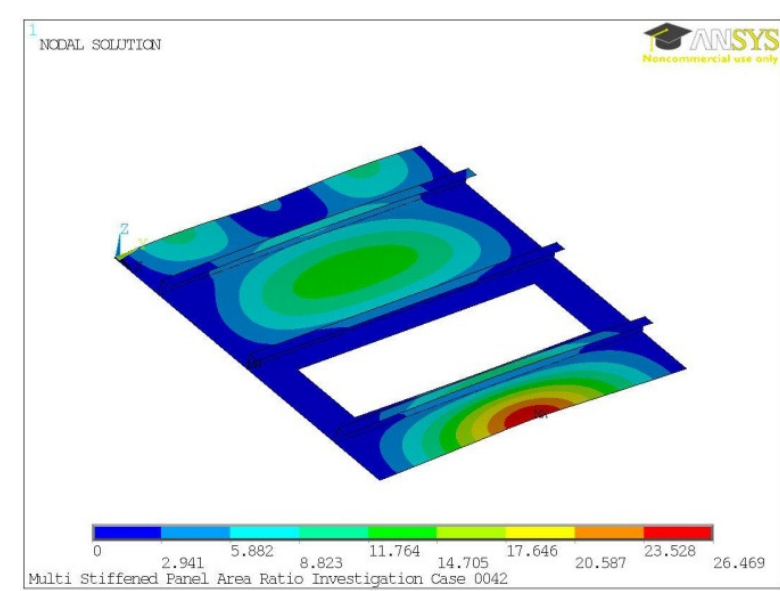

Figure 24(a)

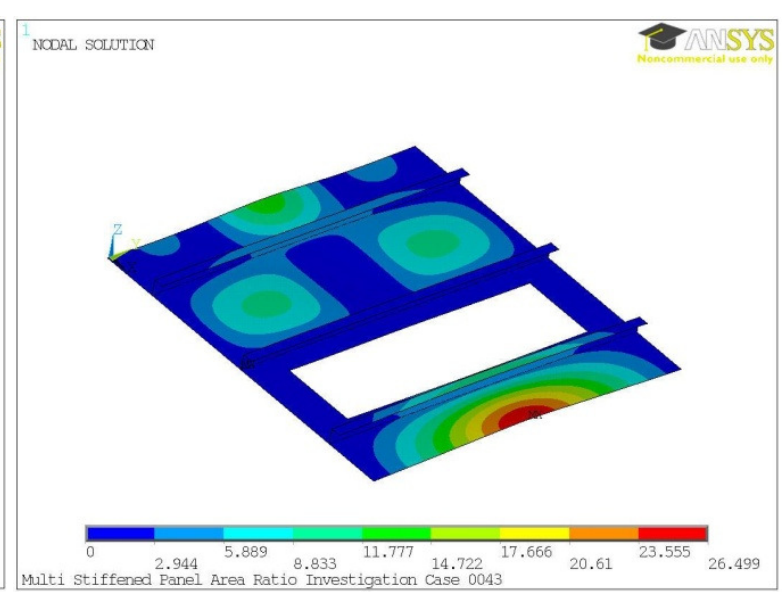

Figure 24(b)

Figure 24 - Displacement plots of three stiffened panel with square damage, plate slenderness ratio 3 and area ratio (a) 0.167 and (b) 0.171 


\section{Discussion}

The investigation has shown that ISUM is able to provide reliable results for predicting the collapse strength of intact stiffened steel panels, by idealizing large panel arrangements as the sum of singularly stiffened plate-stiffener combinations, as shown in Equation (1). Results show that ISUM provides conservative results by a mean of $5.1 \%$ when compared to FEA for the complete panel in the intact condition for the cases assessed.

In a damage scenario, where damage has occurred to the plate between stiffeners, comparisons of ISUM with FEA show ISUM to be conservative by a mean of $65 \%$, caused by the assumptions that are required to model damage by this method. A proposed new ISUM for the assessment of damaged steel-plated structure, whereby the strength of the damaged elements is included in the assessment as shown in Equation (2), has shown that the mean error can be reduced to $4.3 \%$ with a maximum error of $12.4 \%$. It should be noted that application of the new ISUM has shown to provide nonconservative results in some cases. This is due to alternating deflection modes appearing in the surrounding undamaged structure, seen in the full panel FEA, influenced by the damage aperture. This is not captured by the ISUM which, due to separation of the elements using stiffened-plate model, is unable to model the influence of the damage on surrounding structure. Increasing the element size used in the new ISUM would allow this effect to be captured, removing the nonconservative results.

In the case where damage occurs to the central stiffener of a panel, ISUM is shown to be conservative by a mean of $10.7 \%$ and have maximum error of $36.2 \%$. Implementing the new ISUM, mean difference is reduced to $3.7 \%$ with maximum value of $14.4 \%$. In both scenarios, the ISUM has been shown to provide some non-conservative results, due to the influence of the damage aperture on the mode shapes developed in the surrounding structure.

Assessment of the affect of damage aperture shape on the collapse strength of a damaged stiffened panel has shown that the shape has minimal effect, with the mean difference between the cases shown to be less than $2 \%$. Conversely, the damage size plays a large factor in determining the strength of a 
damaged stiffened panel, though the rate of decline in strength is far more controlled than may have been believed. In the case where the plate between stiffeners is damaged but stiffeners remain intact, an almost linear relationship exists between normalised failure load and area ratio for all slenderness ratios assessed. In the case where the damage was located on the central stiffener of the panel, it can be seen that there is a rapid decline in the panel strength in the initial phase as the stiffener is breached, before the rate of decline of normalised failure load with increase in damage area ratio assumes an almost linear relationship again. This shows the importance of accurate determination of the site of damage but not shape. This indicates that future damage modelling of different incidents should concentrate on accurate determination of size of damage and be categorised as such when designing for damage survivability or assessing a damaged steel-plated structure.

It should be noted that in some configurations, fluctuations in normalised failure load occurred, disrupting the orderly trends shown. Investigation into these fluctuations have shown that they are caused by alternating deflection shapes occurring in the undamaged plate, caused due to the particular damage and panel geometry configuration. The fluctuations are not catastrophic to the produced trends, but continue to demonstrate this weakness to ISUM, which is unable to calculate the effect the damage event has on adjoining panels due to the imposed modelling assumptions. In order to assess damaged structures and account for these influences, idealisation of the structure into larger structural units could be necessary. Further work is required to investigate this phenomenon.

This study has demonstrated that a new ISUM incorporating damaged elements can be created; however, to implement the method in its current form would require stress-strain curves to be produced for all possible damage situations for each ISUM element. This remains an unrealistic task due to time constraints for running FEA and the number of possible damage events that could occur. Previous research by the authors $[18,22]$, has indicated that the use of response surface method (RSM) may provide a solution to this problem by being able to capture a large amount of information incorporating multiple variables. RSM can be described as a surface fitting method, capable of capturing multi-dimensional variations [23]. Utilising FEA as the input to the RSM, to benefit from the high level of accuracy possible, the source information required for the response surfaces could be 
created through careful selection of appropriate intact and damaged stiffened panel arrangements. This would allow assessment of both intact and damage events by one calculation method and could be developed to assess larger stiffened panel arrangements as well as stiffened-plate configurations. It is proposed that this method, implemented in a progressive collapse method as a replacement for the current stress-strain curve form of strength data storage, could provide many benefits in the ultimate strength assessment of damaged steel-plated structures and it is intended to continue this work to investigate this potential.

\section{Conclusions}

A need for the rapid assessment of damaged steel-plated structures has been identified for the assessment of accidentally (or deliberately) damaged or aged structure. ISUM has been identified as a potential tool to allow such assessments to be performed.

Assessment of the application of ISUM to calculate the strength of damaged steel plated structures, has been conducted using finite element modelling, verified against previous research. A new ISUM for application to damaged structures has been proposed and demonstrated to be able to provide improved accuracy above the current ISUM. However, the assessment of the ISUM and new ISUM have shown that the inability of the methods to model the influence of the damage on the failure mode shapes developed in the surrounding structure can lead to a non-conservative failure load prediction. Increasing the size of the ISUM elements would allow for this influence to be captured within the analysis. Finally the paper gives recommendations for the treatment of structural damage and further improvements for use within design and emergency response.

\section{Acknowledgements}

The authors would like to thank the UK Ministry of Defence and Lloyd's Register EMEA for their continued support and without whom this research would not have been possible. 


\section{References}

[1] Mahin S.A. (1998). Lessons from damage to steel buildings during the Northridge earthquake. Engineering Structures Vol.20; pp261-270.

[2] Heneka P, Ruck B (2008). A damage model for the assessment of storm damage to buildings. Engineering Structures Vol.30; pp3603-3609.

[3] Fam A, MacDougall C, Shaat A (2009). Upgrading steel-concrete composite girders and repair of damaged steel beams using bonded CFRP laminates. Thin-Walled Structures, 47; pp1122-1135.

[4] Paik J K, Faulkner D (2003). Reassessment of the M.V.Derbyshire sinking with the focus on hull-girder collapse. Journal of Marine Technology, Vol.40; pp258-269.

[5] Jin W-L, Song J, Gong S-f, Lu Y (2005). Evaluation of damage to offshore platform structures due to collision of large barge. Engineering Structures Vol. 27; pp1317 - 1326.

[6] Storhaug G (2009). The 4400TEU container vessel MSC Napoli broke its back, but did whipping contribute? Hydroelasticity in Marine Technology (Hydroelasticity' 2009) proceedings; pp233243.

[7] Wierzbicki T, Teng X (2003). How the airplane wing cut through the exterior columns of the World Trade Centre. International Journal of Impact Engineering, Vol. 28; pp601-625.

[8] ISSC 2009 Committee v.1. Damage assessment after accidental events. $17^{\text {th }}$ International Ship and Offshore Congress (2009).

[9] Ueda Y, Rashed S M H (1974). An ultimate transverse strength analysis of ship structures. Journal of the society of Naval Architects of Japan; 136; pp309 - 324.

[10] Dow R S, Hugill R C, Clark J D, Smith C S (1981). Evaluation of ultimate ship hull strength. Extreme Loads Response Symposium, 1981; pp133-148.

[11] Ueda Y, Rashed S M H (1991). Modern method of ultimate strength analysis of offshore structures. International Journal of Offshore and Polar Engineering; Vol.1, March 1991; pp27-41.

[12] Kaeding P, Fujikubo M. (2002). New simplified model for collapse analysis of stiffened plates and its application to offshore structures. International Journal of Offshore and Polar Engineering; Vol.12; pp398-405.

[13] Ueda Y, Rashed S M H (1984). The idealized unit method and its application to deep girder structures. Computers and Structures; Vol.18; pp277-293.

[14] Paik J, Thayamballi A (2006). Ultimate limit state design of steel-plated structures. John Wiley \& Sons, Ltd.

[15] Paik J, Thayamballi A (2003). A concise introduction to the idealised structural unit method for nonlinear analysis of large plated structures and its application. Thin-Walled Structures 41; pp329-355.

[16] Guedes Soares C, Luis R M, Nikolov P, Downes J, Taczala M, Modiga M, Quesnel T, Toderan C, Samuelides M (2008). Benchmark study on the use of simplified structural codes to predict 
the ultimate strength of a damaged ship hull. International Shipbuilding Progress 55; pp87107.

[17] Smith C S, Dow R S (1981). Residual strength assessment of damaged steel ships and offshore structures. Journal of Constructional Steel Research, Vol.1 Part 4, pp2-15.

[18] Underwood J M, Sobey, A J, Blake J I R, Shenoi R A (2010). Local Stress Sensitivity Analysis of Damaged Steel Ship Hulls. Practical Design of Ships and Other Floating Structures (PRADS 2010) Proceedings; pp1006-1014.

[19] Suneel Kumar M., Alagusundaramoorthy P., Sundaravadivelu R. (2009). "Interaction curves for stiffened panel with circular opening under axial loads". Ships and Offshore Structures Vol.4; pp.133-143.

[20] Assakkaf, A.I., Ayyub, B.M., Mattei, N.J., (2000) Reliability-based load and resistance factor design (LRFD) of hull structural components of surface ships. Association of Scientists and Engineers 37th Annual Technical Symposium,2000; CD.

[21] Hart, D.K., Rutherford, S.E., Wickham, A.H.S., (1985) Structural reliability analysis of stiffened panels. Transactions of the Royal Institution of Naval Architects, vol. 128, pp.293-310.

[22] Sobey A J, Underwood J M, A J, Blake J I R, Shenoi R A (2010). Reliability Analysis of Damaged Steel Structures Using Finite Element Analysis. $5^{\text {th }}$ International ASRANet 2010 Conference; $C D$.

[23] Toal D.J.J., Bressloff N.W., Keane A.J. (2008). Krigging hyperparameter tuning in simulationbased multidisciplinary design optimisation. AIAA Journal, Vol.39, pp2233-2241. 